O $\quad$ R I I G I $\quad$ N A $A$

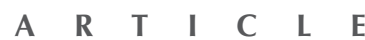

\title{
Dysmenorrhoea among Hong Kong university students: prevalence, impact, and management
}

\author{
CF Chia 謝志峰 \\ Joyce HY Lai 黎可恩 \\ PK Cheung 張柏健 \\ LT Kwong 鄺莉婷 \\ Fiona PM Lau 劉沛雯 \\ KH Leung 梁君豪 \\ MT Leung 梁美迪 \\ Francis CH Wong 黃俊謙 \\ SF Ngu吳庥慧
}

Main outcome measures

Key words

Dysmenorrhea; Prevalence; Young adult

Hong Kong Med J 2013;19:222-8

DOI: $10.12809 / \mathrm{hkmj} 133807$

Li Ka Shing Faculty of Medicine, The University of Hong Kong, Pokfulam,

Hong Kong CF Chia

JHY Lai

PK Cheung

LT Kwong

FPM Lau

KH Leung

MT Leung

FCH Wong

Department of Obstetrics and Gynaecology, The University of Hong Kong, Queen Mary Hospital, Pokfulam,

Hong Kong

SF Ngu, MB, BS, MRCOG

Correspondence to: Dr SF Ngu

Email: ngusiewf@hku.hk

\section{Introduction}

Objective To evaluate the prevalence of dysmenorrhoea, its impact, and management approaches in Hong Kong university students, and to compare between medical and non-medical students for any potential differences in coping strategies.

Design Cross-sectional questionnaire survey.

Setting The University of Hong Kong, Hong Kong.

Participants A total of 240 undergraduate (128 medical and 112 non-medical) students.

Data on the presence and severity of dysmenorrhoea, its impact on daily life, management approaches, specific strategies, and their self-perceived effectiveness were obtained and analysed.

Results In these subjects, the prevalence of dysmenorrhoea was 80\% (95\% confidence interval, $75-85 \%$ ) with a mean (standard deviation) pain score of 5.0 (1.7). The most common impacts on daily life included reduced ability to concentrate and/or disturbance with study (75\%) and changes in normal physical activity $(60 \%)$. Only $6 \%$ sought medical advice, while $70 \%$ practised selfmanagement. Pain scores and pain affecting normal physical activities were important predictive factors for self-management and for management based on pharmacological or nonpharmacological means. The commonest specific strategies used were a warm beverage (62\%), paracetamol (57\%), and sleeping $(45 \%)$, while the most effective strategies were non-steroidal anti-inflammatory drugs $(\mathbf{1 0 0} \%)$, traditional Chinese medicine $(93 \%)$, and dietary/nutritional supplements (92\%). Regarding the comparison of medical and non-medical students, the former used fewer pharmacological strategies among the various management approaches investigated.

Conclusion With data showing dysmenorrhoea as a very common condition having a significant impact in the Hong Kong community, primary care doctors should reassure young women with dysmenorrhoea that it is a common experience in the same age-group. Health education on the existence of effective treatment from medical practitioners could help women whose dysmenorrhoea was not controlled by self-management.

\section{New knowledge added by this study}

Prevalence of dysmenorrhoea among young women in Hong Kong may be as high as $80 \%$.

- The impact of dysmenorrhoea may be underestimated if based on hospital admission data or absenteeism, as changes in normal physical activity and reduced ability to concentrate are what affects most women with dysmenorrhoea.

- Most women with dysmenorrhoea tend to self-manage their symptoms, many of whom selfmedicate, instead of seeking formal medical advice.

Implications for clinical practice or policy

- Primary care doctors can reassure young women with dysmenorrhoea that it is a common experience in subjects of the same age-group.

- Health education on the existence of effective treatment from medical practitioners may help women with dysmenorrhoea not controlled by self-management.

Dysmenorrhoea is experienced as uterine pain or cramps in the lower abdomen, occurring just before and/or during menstruation, with variations among different females. ${ }^{1}$ It has 
been proposed that the release of prostaglandins in the menstrual fluid leads to uterine contractions that give rise to the pain of dysmenorrhoea. ${ }^{1,2}$ Being a common and significantly bothersome health problem, particularly affecting young women, dysmenorrhoea is a significant problem and worthy of study.

The prevalence of dysmenorrhoea among young women varies widely from country to country. Studies of university students showed its prevalence to be $64 \%$ in Nigeria $^{3}$ and Mexico, ${ }^{4} 84 \%$ in Thailand, ${ }^{5}$ $88 \%$ in Turkey, ${ }^{6}$ and $93 \%$ in Taiwan. ${ }^{7}$ Studies of high school students also revealed diverse dysmenorrhoea prevalence rates, being $48 \%$ in Mexico, ${ }^{8} 72 \%$ in Ethiopia, ${ }^{9}$ and $93 \%$ in Australia. ${ }^{10}$ In a local study on secondary school girls, its prevalence was $69 \%{ }^{11}$

Being such a common experience, it causes considerable disturbance in the daily activities of young women, which includes school absenteeism. In a study from Mexico, $65 \%$ of women interviewed recounted limitation in daily activities and $42 \%$ reported absenteeism, ${ }^{4}$ while a local study found that only $10 \%$ had taken sick leave due to dysmenorrhoea. ${ }^{11}$ In other studies, $64 \%$ women had reported low concentration in class, ${ }^{5}$ and among those with dysmenorrhoea, 1.5 times as many subjects reported depression as those without this problem. ${ }^{3}$

Young women cope with their dysmenorrhoea using different approaches. According to the study from Mexico, $62 \%$ of university students with dysmenorrhoea self-medicated while $26 \%$ consulted physicians. ${ }^{4}$ A US study ${ }^{12}$ showed that apart from medication, all adolescent girls used nonpharmacological remedies such as sleeping and heat application to soothe pains due to dysmenorrhoea. Approaches to deal with dysmenorrhoea differ in different cultures.

We believe that understanding about dysmenorrhoea may be limited among many young women, as they receive little health education on this subject. Moreover, lack of past encounters with chronic pain and suffering may also influence the subjective perception of pain. On the other hand, medical students represent a population with better knowledge and exposure to other forms of chronic suffering, which possibly results in different pain perception and subsequent decisions on coping approaches.

This study aimed to evaluate the prevalence of dysmenorrhoea, its impact, and the management strategies adopted by local university students, as well as a comparison between medical and nonmedical students for any potential differences in coping strategies.

\section{Methods}

Across-sectional questionnaire survey was conducted

\section{經痛在香港大學生之間的現患率、影響及 處理方法}

目的 檢視經痛在香港大學生之間的現患率、其影響及相應 的處理方法, 並比較醫科生和非醫科生經痛時所使用 的不同處理方法。

設計 横斷面問卷調查。

安排 香港大學。

參與者 240 名香港大學本科生（包括128名醫科生及112名非 醫科生）。

主要結果測量 了解受訪者是否有經痛、其嚴重程度、對日常生活的 影響、處理方針、對應方法及自我評估的有效程度， 以作分析。

結果 經痛的患病率為80\%（95\%置信度75-85\%），而平均 (標準差) 痛楚水平則為5.0（1.7）。對日常生活最 普遍的影響包括專注力下降與學習受干擾 $(75 \%)$ 以 及正常體能活動的轉變（60\%）。只有少數（6\%） 經痛患者尋求醫生意見, 而70\%會自行處理。痛楚 水平及影響正常體能活動的痛楚都是影響患者決定 自行處理、採用藥物和非藥物處理的重要因素。最 常被採納的對應方法有领用熱飲（62\%）、使用撲熱 息痛 $(57 \%)$ 和睡眠 $(45 \%)$ ；而被認為最有效的方 法則為使用非類固醇類消炎止痛藥（100\%）、中藥 （93\%）或進食營養補充品（92\%）。與非醫科生比 較, 醫科生經痛時會較少採用藥物處理的方法。

結論數據指出經痛在香港十分普遍, 影響明顯。基層醫療 醫生可引用此數據, 向年輕患者指出很多同年齡組別 的女士都有經痛的相同體驗。就醫生可提供的有效治 療進行健康教育, 對經痛在自行處理下未能受控的患 者有所幫助。 at The University of Hong Kong. Ethical approval was obtained from the Institutional Review Board of The University of Hong Kong/Hospital Authority Hong Kong West Cluster. Women aged 18 to 25 years, who were undergraduate students at The University of Hong Kong and gave their consent independently were recruited for this questionnaire survey. Exclusion criteria were absence of menstruation throughout the past 6 months and any history of pelvic pathologies. Returned questionnaires, which contained missing responses regarding demographic or menstrual characteristics, were also excluded from the analysis.

A convenience sample of 139 medical students (ie students studying for the degree of Bachelor of Medicine and Bachelor of Surgery at The University of Hong Kong) and 117 non-medical students were invited to complete a questionnaire (Appendix) from January to June 2011. Medical students were approached after whole-class sessions and non- 
medical students were approached at residential halls in the university. All women participated in this study on a voluntary basis. Four women were excluded from the analysis due to a history of pelvic pathologies (including dermoid cyst, cervical cancer, sexually transmitted disease, and non-specific vaginitis); 12 other women (9 medical and 3 non-medical students) were also excluded because of incomplete responses on demographic or menstrual characteristics. A total of 240 women (128 medical students and 112 nonmedical students) were therefore included in the final analysis.

The questionnaire addressed the frequency and timing of dysmenorrhoea within a cycle over the past 6 months. The impact of dysmenorrhoea was assessed through any occurrence of events such as hospital admission, absence from school/college, changes in normal physical activity, reduced ability to concentrate and/or disturbance with study, sleep disturbance, and adverse effect on psychosocial wellbeing in the past 6 months. Participants were also asked to rate the severity of their dysmenorrhoea using a numerical rating scale with a range of 1 (mildest pain) to 10 (worst pain).

Their management strategies for dysmenorrhoea were also investigated. This addressed how frequently they would consult formal medical advice, and how often selfmanagement was used. We also presented them with a list of pharmacological and non-pharmacological management approaches (identified from our own experience and a literature review), $, 7,8,12,13$ and asked whether they had ever adopted any of these in the past 6 months. If so, they were asked to rate the respective self-perceived effectiveness of each method on a binary scale.

\section{Statistical analysis}

Data were analysed using commercially available software (SPSS 19.0; SPSS Inc., Chicago [IL], US). Prevalence of dysmenorrhoea and its attributes, such as the mean perceived pain scores and frequency of dysmenorrhoea among medical and non-medical students were calculated. Pearson Chi squared tests for association and independent $t$ tests for two samples were used to compare the differences in proportions and means between the two groups.

To study the potential influence of demographic and menstrual backgrounds on the presence of dysmenorrhoea in medical and non-medical students, binary logistic regression was used to calculate the adjusted odds ratios of dysmenorrhoea in these two groups, with adjustments for covariates including their age, age at menarche, number of periods in the past 6 months, regularity of cycles, and average cycle length.

Proportions of management strategies among women with dysmenorrhoea in the two groups were calculated. Pearson Chi squared tests for association were applied to assess the proportional differences for each management strategy in the two groups. Any $\mathrm{P}$ value of $<0.05$ was considered statistically significant.

To further study the pattern of management approaches, binary logistic regression analyses were performed on whether formal medical advice was obtained, whether self-management was practised, whether pharmacological strategies were adopted, and whether non-pharmacological strategies were adopted (as dependent variables). Covariates entered included age, age at menarche, status as medical or non-medical student, number of periods and periods

TABLE I. Menstrual characteristics, prevalence, and characteristics of dysmenorrhoea

\begin{tabular}{|c|c|c|c|c|}
\hline Characteristic & All $(n=240)$ & $\begin{array}{l}\text { Medical students } \\
(n=128)\end{array}$ & $\begin{array}{c}\text { Non-medical } \\
\text { students }(n=112)\end{array}$ & P value* \\
\hline Mean age (years) & 20.1 & 19.8 & 20.4 & 0.001 \\
\hline Mean age of menarche (years) & 12.5 & 12.4 & 12.7 & 0.013 \\
\hline Mean $( \pm \mathrm{SD})$ No. of periods in the past 6 months & $5.5 \pm 1.0$ & $5.5 \pm 1.1$ & $5.6 \pm 0.8$ & 0.203 \\
\hline Proportion of subjects with regular period & $70 \%$ & $72 \%$ & $69 \%$ & 0.597 \\
\hline Prevalence of dysmenorrhoea & $191(80 \%)$ & $99(77 \%)$ & $92(82 \%)$ & 0.357 \\
\hline \multicolumn{5}{|l|}{ Subjects with dysmenorrhoea } \\
\hline Mean $( \pm \mathrm{SD})$ No. of periods with dysmenorrhoea in the past 6 months & $3.4 \pm 1.9$ & $3.4 \pm 1.9$ & $3.5 \pm 2.0$ & 0.622 \\
\hline Dysmenorrhoea ratio in past 6 months $^{\dagger}$ & $63 \%$ & $62 \%$ & $64 \%$ & 0.706 \\
\hline Have pre-menstrual pain & $98(51 \%)$ & $26(26 \%)$ & $72(78 \%)$ & $<0.001$ \\
\hline Have pain at the beginning of period & $117(61 \%)$ & $88(89 \%)$ & $29(32 \%)$ & $<0.001$ \\
\hline Have pain in the middle of period & $20(11 \%)$ & $14(14 \%)$ & $6(7 \%)$ & 0.086 \\
\hline Have pain towards the end of period & $3(2 \%)$ & $2(2 \%)$ & $1(1 \%)$ & 0.604 \\
\hline
\end{tabular}

* Tests on mean or proportional differences between medical and non-medical students

+ Dysmenorrhoea ratio $=$ No. of periods with dysmenorrhoea $/$ total No. of periods in the past 6 months 
with dysmenorrhoea in the past 6 months, regularity of cycles, average length of each cycle, time of pain within the period, as well as severity and impact of the pain.

\section{Results}

For the 240 women, their mean $( \pm$ SD) age was 20.1 \pm 1.4 years and the mean age at menarche was $12.5 \pm$ 1.2 years. In the past 6 months, their mean number of periods was $5.5 \pm 1.0$ and $70 \%$ had regular periods. The prevalence of dysmenorrhoea among these university students was $80 \%$ (95\% confidence interval, $75-85 \%$ ). Also, they experienced dysmenorrhoea during a mean of $3.4 \pm 1.9$ periods, which was equivalent to $63 \%$ of all their periods. Medical students and non-medical students had different pain patterns; the former had less pre-menstrual pain $(26 \%$ vs $78 \%$; $\mathrm{P}<0.001)$ but more pain at the beginning of their period $(89 \%$ vs $32 \% ; \mathrm{P}<0.001$ ) [Table 1].

The odds of having dysmenorrhoea decreased by $30 \%$ when the age of menarche increased by 1 year $(\mathrm{P}=0.016)$. The odds was 8 -fold higher in women with average period lengths of 7 to 9 days as opposed to those with periods lasting less than 3 days $(\mathrm{P}=0.018)$ [Table 2].

In women with dysmenorrhoea, the mean $( \pm \mathrm{SD})$ pain score was $5.0 \pm 1.7$, with no significant difference $(\mathrm{P}=0.603)$ between medical and non-medical university students. Other behavioural indicators of its impact, arranged in descending order of prevalence, included reduced ability to concentrate and/or disturbance with study $(75 \%)$, changes in normal physical activity $(60 \%)$, adverse effect on psychosocial well-being (36\%), sleep disturbance (26\%), absence from school (19\%), and hospital admission (3\%). Among these indicators, medical students tended to have less absenteeism than nonmedical students $(11 \%$ vs $27 \%$; $P=0.005)$. No significant difference was found for all other indicators (Table 3 ).

For management approaches to dysmenorrhoea, only $6 \%$ consulted formal medical advice, while $70 \%$ practised self-management. Medical students tended not to manage their dysmenorrhoea compared with non-medical students $(39 \%$ vs $16 \% ; \mathrm{P}<0.001)$, especially with pharmacological strategies (45\% vs $79 \%$; $\mathrm{P}<0.001)$. They also practised less self-management $(60 \%$ vs $80 \% ; \mathrm{P}=0.002$ ) and less non-pharmacological management strategies $(75 \%$ vs $91 \% ; \mathrm{P}=0.002)$ than non-medical students (Table 4).

Several factors were evaluated for their influences on management approaches to dysmenorrhoea (Table 5), some of which were significant as follows. Changes in normal physical activity with dysmenorrhoea was significantly associated with women who practised selfmanagement, as well as adopting pharmacological and non-pharmacological strategies. Moreover, the odds on whether formal medical advice was consulted was 5.55 times higher for each year's delay of menarche. The odds on whether self-management was practised was 1.41 times higher per unit increase in the 10-point pain severity rating scale. Women were more likely to adopt a pharmacological strategy if they had an average period length of 4 to 6 days, and less likely if they were medical students or had pain at the beginning of the period. Such odds was

TABLE 2. Binary logistic regression on menstrual characteristics and other factors in influencing dysmenorrhoea development

\begin{tabular}{lcc}
\hline Item & $\begin{array}{c}\text { Odds ratio (95\% } \\
\text { confidence interval) }\end{array}$ & P value \\
\hline Students' age & $0.97(0.76-1.24)$ & 0.823 \\
\hline Age of menarche & $0.70(0.52-0.94)$ & 0.016 \\
No. of periods in the past 6 months & $1.03(0.70-1.51)$ & 0.878 \\
Regularity of cycles & $0.50(0.21-1.20)$ & 0.121 \\
\hline Average length of each period (days) & & \\
\hline \multicolumn{1}{|c|}{ 4-6 vs $\leq 3$} & $1.72(0.59-5.05)$ & 0.321 \\
\hline 7-9 vs $\leq 3$ & $8.39(1.43-49.19)$ & 0.018 \\
Being a medical student & $0.58(0.29-1.17)$ & 0.129 \\
\hline
\end{tabular}

TABLE 3. Impact of dysmenorrhoea within the past 6 months in dysmenorrhoea subgroup analysis

\begin{tabular}{|c|c|c|c|c|}
\hline Impact of dysmenorrhoea & All $(n=191)$ & $\begin{array}{l}\text { Medical students } \\
(\mathrm{n}=99)\end{array}$ & $\begin{array}{c}\text { Non-medical } \\
\text { students }(n=92)\end{array}$ & $\mathbf{P}_{\text {value }}^{\dagger}$ \\
\hline Mean $( \pm S D)$ pain severity score (by NRS in scale of $1-10)^{\star}$ & $5.0 \pm 1.7$ & $5.0 \pm 2.0$ & $4.9 \pm 1.5$ & 0.603 \\
\hline Hospital admission & $5(3 \%)$ & $2(2 \%)$ & $3(3 \%)$ & 0.592 \\
\hline Absence from school & $36(19 \%)$ & $11(11 \%)$ & $25(27 \%)$ & 0.005 \\
\hline Sleep disturbance & $49(26 \%)$ & $30(30 \%)$ & $19(21 \%)$ & 0.127 \\
\hline Adverse effect on psychosocial well-being & $68(36 \%)$ & $39(39 \%)$ & $29(32 \%)$ & 0.256 \\
\hline Changes in normal physical activity & $114(60 \%)$ & $54(55 \%)$ & $60(65 \%)$ & 0.133 \\
\hline Reduced ability to concentrate and/or disturbance with study & $143(75 \%)$ & $71(72 \%)$ & $72(78 \%)$ & 0.298 \\
\hline
\end{tabular}

* SD denotes standard deviation, and NRS numerical rating scale

+ Tests on mean or proportional differences between medical and non-medical students 
1.32 times for one more cycle with dysmenorrhoea in the past 6 months and 1.49 times higher for each score increase in pain severity. Women were less likely to adopt a non-pharmacological strategy if they had pain at the beginning or towards the end of the period. The respective odds were 1.46 times and 1.65 times higher for one more cycle with dysmenorrhoea in the past 6 months and for each score increase in pain severity.

Interestingly, the most commonly adopted strategies for management of dysmenorrhoea (Table 6) were not always the ones that were selfperceived as most successful. The most adopted strategies were recourse to a warm beverage (62\%), paracetamol $(57 \%)$, and sleeping $(45 \%)$. However, the self-perceived success rates were ranked as recourse to non-steroidal anti-inflammatory drugs (NSAID) which were universally effective $(100 \%)$, followed by traditional Chinese medicine (93\%) and dietary/ nutritional supplements (92\%).

TABLE 4. Management approaches of dysmenorrhoea in the past 6 months

\begin{tabular}{|c|c|c|c|c|}
\hline Management & All $(n=191)$ & $\begin{array}{l}\text { Medical students } \\
\qquad(n=99)\end{array}$ & $\begin{array}{l}\text { Non-medical } \\
\text { students }(n=92)\end{array}$ & P value* \\
\hline \multicolumn{5}{|l|}{ Where to seek help? } \\
\hline Consulted formal medical advice & $11(6 \%)$ & $3(3 \%)$ & $8(9 \%)$ & 0.093 \\
\hline Practised self-management & $133(70 \%)$ & $59(60 \%)$ & $74(80 \%)$ & 0.002 \\
\hline None of the above & $54(28 \%)$ & $39(39 \%)$ & $15(16 \%)$ & $<0.001$ \\
\hline \multicolumn{5}{|l|}{ What to use? } \\
\hline Pharmacological & $118(62 \%)$ & $45(45 \%)$ & $73(79 \%)$ & $<0.001$ \\
\hline Without formal medical advice & 107 (56\%) & $41(41 \%)$ & $66(72 \%)$ & $<0.001$ \\
\hline Non-pharmacological & $158(83 \%)$ & $74(75 \%)$ & $84(91 \%)$ & 0.002 \\
\hline
\end{tabular}

TABLE 5. Logistic regression on different factors influencing management strategies in dysmenorrhoea subgroup analysis ${ }^{*}$

\begin{tabular}{|c|c|c|c|c|}
\hline \multirow[t]{2}{*}{ Factor } & \multicolumn{2}{|c|}{ Where to seek help? } & \multicolumn{2}{|c|}{ What to use? } \\
\hline & Formal medical advice & Self-management & Pharmacological & Non-pharmacological \\
\hline Student's age & $0.93(0.38-2.31,0.883)$ & $0.96(0.73-1.26,0.766)$ & $0.98(0.74-1.29,0.862)$ & $0.95(0.66-1.37,0.783)$ \\
\hline Age of menarche & $5.55(1.29-23.94,0.022)$ & $1.06(0.72-1.57,0.756)$ & $1.26(0.86-1.85,0.238)$ & $1.46(0.85-2.52,0.171)$ \\
\hline Status as a medical student & $0.13(0.00-15.00,0.395)$ & $0.41(0.15-1.11,0.079)$ & $0.28(0.10-0.77,0.013)$ & $0.41(0.11-1.56,0.191)$ \\
\hline No. of period in the past 6 months & $1.70(0.40-7.21,0.474)$ & $1.18(0.77-1.81,0.454)$ & $1.05(0.67-1.63,0.841)$ & $1.35(0.71-2.55,0.362)$ \\
\hline With dysmenorrhoea & $1.22(0.71-2.11,0.472)$ & $1.15(0.93-1.43,0.205)$ & $1.32(1.04-1.66,0.020)$ & $1.46(1.04-2.04,0.028)$ \\
\hline Regular cycles & $1.73(0.17-17.55,0.642)$ & $0.84(0.33-2.15,0.722)$ & $0.83(0.33-2.12,0.698)$ & $0.33(0.07-1.63,0.175)$ \\
\hline \multicolumn{5}{|l|}{ Average length of each period (days) } \\
\hline $4-6$ vs $\leq 3$ & $0.12(0.00-3.57,0.220)$ & $2.67(0.62-11.53,0.189)$ & $5.75(1.18-28.02,0.031)$ & $3.92(0.40-38.02,0.239)$ \\
\hline $7-9$ vs $\leq 3$ & $1.89(0.05-65.62,0.726)$ & $2.07(0.36-11.91,0.416)$ & $5.42(0.84-35.08,0.076)$ & $2.99(0.22-40.49,0.410)$ \\
\hline \multicolumn{5}{|l|}{ Timing of pain } \\
\hline During pre-menstrual period & $0.18(0.00-19.57,0.476)$ & $1.79(0.62-5.21,0.286)$ & $0.91(0.32-2.59,0.859)$ & $0.90(0.22-3.67,0.887)$ \\
\hline At the beginning of period & $0.06(0.00-9.08,0.267)$ & $0.74(0.22-2.47,0.618)$ & $0.20(0.06-0.72,0.013)$ & $0.08(0.01-0.44,0.004)$ \\
\hline In the middle of period & $11.2(0.19-657.51,0.246)$ & $4.15(0.91-18.87,0.065)$ & $0.77(0.22-2.64,0.675)$ & $2.50(0.36-17.48,0.356)$ \\
\hline Towards the end of period & - & $0.04(0.00-1.22,0.065)$ & $0.42(0.02-8.54,0.573)$ & $0.02(0.00-0.65,0.029)$ \\
\hline Severity of pain & $1.54(0.59-4.02,0.376)$ & $1.41(1.09-1.82,0.008)$ & $1.49(1.16-1.92,0.002)$ & $1.65(1.15-2.38,0.007)$ \\
\hline \multicolumn{5}{|l|}{ Impact of pain } \\
\hline Hospital admission & $16.46(0.29-922.29,0.173)$ & - & - & $0.06(0.00-2.14,0.123)$ \\
\hline Absence from school & $3.07(0.27-35.17,0.368)$ & $0.72(0.22-2.32,0.584)$ & $2.25(0.59-8.55,0.233)$ & $0.26(0.05-1.40,0.117)$ \\
\hline Changes in normal physical activity & $167.11\left(0.01-2.21 \times 10^{6}, 0.290\right)$ & $2.93(1.21-7.10,0.017)$ & $2.47(1.03-5.94,0.043)$ & $8.10(1.97-33.41,0.004)$ \\
\hline $\begin{array}{l}\text { Reduced ability to concentrate and/ } \\
\text { or disturbance with study }\end{array}$ & - & $1.78(0.69-4.63,0.235)$ & $1.57(0.59-4.23,0.368)$ & $1.07(0.26-4.32,0.928)$ \\
\hline Sleep disturbance & $15.48(0.66-362.73,0.089)$ & $0.58(0.23-1.47,0.250)$ & $0.79(0.32-1.94,0.603)$ & $0.74(0.19-2.85,0.665)$ \\
\hline Psychosocial well-being & $0.10(0.01-1.38,0.085)$ & $0.94(0.40-2.23,0.889)$ & $0.76(0.32-1.78,0.521)$ & $1.29(0.38-4.34,0.682)$ \\
\hline
\end{tabular}

* Data are shown as odds ratio (95\% confidence interval, $\mathrm{P}$ value) 


\section{Discussion}

The prevalence of dysmenorrhoea in our subjects was $80 \%$, but any comparison with other studies should be cautiously interpreted as definitions of dysmenorrhoea vary between studies, there being no universal or standard definitions. In our study, the prevalence depended on self-reported presence or absence of dysmenorrhoea in the past 6 months. Other studies used different durations. ${ }^{3-8,11}$ Nevertheless, our finding is similar to the reported prevalence of 64 to $93 \%$ among university students from other regions, ${ }^{3-8}$ and comparable to the prevalence of $69 \%$ in another local study focused on secondary school students. ${ }^{11}$ Regarding factors associated with the development of dysmenorrhoea, similar findings have also been reported in the literature with respect to a positive correlation with earlier menarche $\mathrm{e}^{5,11}$ and longer durations of menstrual periods ( $\geq 7$ days). ${ }^{14}$

In our study, the mean $( \pm S D)$ pain score was $5.0 \pm 1.7$, which was similar to the score of $5.4 \pm 2.3$ reported in another study. ${ }^{4}$ Comparison with other studies was limited as they often entailed only a categorical analysis $5^{5,8,10,14}$ and/or used different measures to evaluate menstruation, like menstrual distress questionnaire, ${ }^{7}$ a multidimensional scoring system, ${ }^{5,14}$ and visual analogue scales. ${ }^{4,5,8,14}$

Despite the impacts quantified for comparison with other studies and countries being relatively few (hospitalisation or absenteeism), 4,10 easily unnoticed and overlooked impacts on personal life were very common in Hong Kong. In our study, $75 \%$ of women with dysmenorrhoea had reduced ability to concentrate and/or disturbance with study. Moreover, $60 \%, 36 \%$ and $26 \%$ of them had changes in physical activity, reduced psychosocial well-being, and sleep disturbance, respectively. As young women are in their most active years, the burden of dysmenorrhoea on their lives appears particularly significant.

Despite such an impact on their lives, very few women we studied $(6 \%)$ sought formal medical advice for their dysmenorrhoea, which was similar to the $4 \%$ reported in a local study on adolescent girls. ${ }^{11}$ This is probably because many women consider pain as a normal part of menstruation, and prefer avoiding medical contact as far as possible due to embarrassment. Owing to the small sample in this series, regression analysis on factors associated with this behaviour was likely to be erroneous and the positive associations observed with age of menarche might be spurious. Notably, $56 \%$ of the women with dysmenorrhoea self-medicated, particularly the non-medical students $(72 \%)$ who might not have much medical knowledge. Although this figure is lower than what was found in a Mexican study, ${ }^{4}$ it is important to know whether the women were clear about the indications, contra-indications, and sideeffects of the various drugs used.
TABLE 6. Adoption rates and self-perceived success rates of various management strategies in dysmenorrhoea subgroup analysis*

\begin{tabular}{lcc}
\hline Management strategy & Adoption rate (\%) & $\begin{array}{c}\text { Self-perceived } \\
\text { success rate (\%) }\end{array}$ \\
\hline Pharmacological & 57 & 56 \\
\hline Panadol & 23 & 100 \\
\hline NSAID & 7 & 93 \\
\hline TCM & 3 & - \\
\hline Others & & 50 \\
\hline Non-pharmacological & 62 & 64 \\
\hline Warm beverage & 45 & 58 \\
\hline Sleeping & 40 & 77 \\
\hline Postural adjustments & 34 & 51 \\
\hline Warm water bag & 22 & 47 \\
\hline Exercise & 17 & 92 \\
\hline Chocolate & 6 & - \\
\hline Dietary/nutritional supplements & 14 & 5 \\
\hline Others & $6 v$ & 5 \\
\hline
\end{tabular}

NSAID denotes non-steroidal anti-inflammatory drugs, and TCM traditional Chinese medicine

Pain scores and pain affecting normal physical activities were associated with the adoption of some of the management approaches studied, and represented the major triggers for management. Women with periods of longer duration and higher frequency were more likely to adopt pharmacological strategies, possibly due to more prolonged and frequent suffering. Negative associations were evident for pain at the beginning of a cycle for both pharmacological and non-pharmacological approaches, and between pain towards the end of the cycle and non-pharmacological approaches. This behaviour could be because women expected the pain to subside with time without management at the beginning of cycle, as well as tolerance of end of cycle pain without resorting to pharmacological control.

Warm beverages, paracetamol, and sleeping were among the commonest management strategies adopted, despite less self-perceived success, which was probably due to their convenience and easy availability. Consistent with medical knowledge, NSAID were very effective but not commonly resorted to, probably because they were prescription drugs and associated with more side-effects. Lack of knowledge about NSAID being effective may also be a contributory factor. Traditional Chinese medicine and dietary/nutritional supplements included a wide variety of actual regimens generally found to be effective. More research is required on the potential mechanisms behind the use of such alternative therapies, which might guide the development of future management strategies. 
Regarding the comparison of medical and nonmedical students, most of the characteristics of their dysmenorrhoea were similar. However, the former exhibited less absenteeism possibly because their classes were more likely to be mandatory and/or vital, not to be missed learning opportunities. Moreover, constant exposure of medical students to patients with all kinds of suffering minimises the importance of dysmenorrhoea as a symptom. However, after controlling for confounders, the only statistically significant difference observed was that medical students used fewer pharmacological strategies among the various management approaches investigated. This may be due to their greater awareness about the potential side-effects of these drugs. There was no biologically plausible reason why medical students reported less pre-menstrual pain but more pain early on during their menstruation.

Regarding limitations of this study, only a few variables were addressed. Several factors that might affect menstrual outcome were not considered, including smoking, obesity, stress, parity, sexual history, menstrual flow, passage of blood clots, and family history. Furthermore, this study was limited to university students, and was not designed primarily to assess the effectiveness of various management strategies, so findings on this issue should only be considered as showing trends. This study mainly served as an insight for further studies on this field that should adopt more rigorous designs to address the aforementioned issues.

\section{Conclusion}

Dysmenorrhoea was very common in Hong Kong university students, and the associated pain could be severe and significantly impact their daily lives. Although very few of them sought formal medical advice, family doctors who encounter such patients should reassure them that it is a common experience (affecting $80 \%$ women in their age-group). As most of them did not seek formal medical advice, knowledge about effective treatment should be promoted via public health efforts. This could empower those whose symptoms are not controlled by nonpharmacological means to seek effective drug treatment (eg NSAID) from medical practitioners.

\section{Acknowledgement}

The authors greatly appreciate the statistical support from Ms Patsy Chau from the Department of Community Medicine, The University of Hong Kong. This study was conducted by medical students as a Health Research Project submitted to Department of Community Medicine, Li Ka Shing Faculty of Medicine, The University of Hong Kong, Hong Kong.

\section{Appendix}

Additional material related to this article can be found on the HKMJ website. Please go to <http://www.hkmj. org $>$, search for the appropriate article, and click on Full Article in PDF following the title.

\section{References}

1. Harel Z. Dysmenorrhea in adolescents and young adults: etiology and management. J Pediatr Adolesc Gynecol 2006;19:363-71. cross ref

2. Fraser IS. Prostaglandins, prostaglandin inhibitors and their roles in gynaecological disorders. Baillieres Clin Obstet Gynaecol 1992;6:829-57. cross ref

3. Titilayo A, Agunbiade OM, Banjo O, Lawani A. Menstrual discomfort and its influence on daily academic activities and psychosocial relationship among undergraduate female students in Nigeria. Tanzan J Health Res 2009;11:181-8.

4. Ortiz MI. Primary dysmenorrhea among Mexican university students: prevalence, impact and treatment. Eur J Obstet Gynecol Reprod Biol 2010;152:73-7. cross ref

5. Tangchai K, Titapant V, Boriboonhirunsarn D. Dysmenorrhea in Thai adolescents: prevalence, impact and knowledge of treatment. J Med Assoc Thai 2004;87(Suppl 3):S69-73.

6. Polat A, Celik H, Gurates B, et al. Prevalence of primary dysmenorrhea in young adult female university students. Arch Gynecol Obstet 2009;279:527-32. cross ref

7. Cheng HF, Lin YH. Selection and efficacy of self-management strategies for dysmenorrhea in young Taiwanese women. J Clin Nurs 2011;20:1018-25. cross ref

8. Ortiz MI, Rangel-Flores E, Carrillo-Alarcón LC, Veras-Godoy HA. Prevalence and impact of primary dysmenorrhea among Mexican high school students. Int J Gynaecol Obstet 2009;107:240-3. cross ref

9. Zegeye DT, Megabiaw B, Mulu A. Age at menarche and the menstrual pattern of secondary school adolescents in northwest Ethiopia. BMC Womens Health 2009;9:29. cross ref

10. Parker MA, Sneddon AE, Arbon P. The menstrual disorder of teenagers (MDOT) study: determining typical menstrual patterns and menstrual disturbance in a large populationbased study of Australian teenagers. BJOG 2010;117:18592. cross ref

11. Chan SS, Yiu KW, Yuen PM, Sahota DS, Chung TK. Menstrual problems and health-seeking behaviour in Hong Kong Chinese girls. Hong Kong Med J 2009;15:18-23.

12. O'Connell K, Davis AR, Westhoff C. Self-treatment patterns among adolescent girls with dysmenorrhea. J Pediatr Adolesc Gynecol 2006;19:285-9. cross ref

13. Mirbagher-Ajorpaz N, Adib-Hajbaghery M, Mosaebi F. The effects of acupressure on primary dysmenorrhea: a randomized controlled trial. Complement Ther Clin Pract 2011;17:33-6. cross ref

14. Unsal A, Ayranci U, Tozun M, Arslan G, Calik E. Prevalence of dysmenorrhea and its effect on quality of life among a group of female university students. Ups J Med Sci 2010;115:138-45. cross ref 